UDC: $9.371 .212: 371.26 \quad$ https://doi.org/10.22190/JTESAP2003283N

\title{
A STUDY OF ARAB UNDERGRADUATE BUSINESS STUDENTS RESPONSE TO TEXT ADAPTATION
}

\author{
Larysa Nikolayeva \\ Zayed University, UAE \\ E-mail: larysa.nikolayeva@gmail.com
}

\begin{abstract}
Current research explores the response of Arab undergraduate Business students to text adaptation. The data was collected in Majan University College, Oman, during the academic year 2018 - 2019. Incorporated at the time of developing learning aids, students' response can serve as one of the tools for enhancing students' language skills required for their academic success. The analysis is based on the response of two mixed-gender groups of students (23 and 31 students respectively) obtained through a micro test and a text difficulty survey addressing their comprehension skills of authentic versus adapted texts. The effect of the text and sentence length, grammatical complexity, and academic vocabulary on students' comprehension were considered in the study. The research demonstrates the need for amending the text for Arab students, identifies the areas of concern and helps material designers working in the Arab world to choose the most linguistically and culturally appropriate approaches to text manipulation.
\end{abstract}

Key words: text adaptation, reader response, academic reading, language skills.

\section{INTRODUCTION}

Equipping students with reading and comprehension skills enables their interaction with the world of knowledge required for further development and success. Reading plays one of the most important parts in the study of the English language. The aim of the tutor is to ensure that his/her students do not just mechanically process the text while reading but that they understand it, learn from it and use this knowledge to enrich their life experience. Reading is an infinite source of information that is available to the audience at any point of time. Our role as educators is to motivate and encourage our students to use it supporting the development of their reading skills. One of the ways to do so is to design teaching materials that would enhance students' willingness to read, improve their language competence and so impact their academic achievements positively.

\section{PURPOSE OF THE STUDY}

Current research aims to compare three types of response, objective, behavioral and subjective, to authentic and adapted text difficulty. It is meant to explore (1) the effect of reading materials authenticity on students' comprehension \& performance, and (2) identify

Submitted September $15^{\text {th }}, 2020$, accepted for publication October $27^{\text {th }}, 2020$ 
the relationship between behavioral and subjective types of response to text difficulty and (3) identify the most problematic aspect of the text.

\section{RESEARCH QUESTIONS}

1. What is the impact of objective response on behavioral response to text difficulty?

2. What is the relation (if any) between behavioral and subjective types of response to text difficulty?

3. What is the role of tutor opinion in text manipulation?

4. What is the most problematic aspect of text comprehension?

\section{LITERATURE REVIEW}

International teachers of reading usually face a dilemma of choice between authentic and adapted reading materials. The followers of authentic reading materials often insist on the advantage of cultural component presence in the text (Roberts 2014; Goodman \& Freeman 2013; Case 2012; Kuimova \& Kobzeva 2011), natural grammar and language use and the need to provide students with a text exceeding their reader ability. On the other hand, components belonging to a different culture might have a negative impact on students' comprehension (Murphy 2013;). Text appropriateness is a matter of concern when it comes to substantial background difference of eastern and western cultures and it is especially relevant in the context of the Arab world. Natural grammar structures used for conveying content related ideas is another argument supporting text authenticity, whereas simplified grammar of adapted texts can sometimes appear more difficult to the reader than its original version (Long \& Ross,1993; Roberts 2014) instead of making it more readable (Crossley \& McNamara 2016). At the same time, it is claimed that students do not comprehend a text produced by a native speaker in the same way as native speakers do, so consequently, a text should not exceed students' capabilities to a great extent (Krashen 1988). Others, on the contrary, say that students are able to understand. Ability of the reader is also a matter to consider before choosing a particular type of the text. It is directly related to students' motivation as well. A text that is beyond student's comprehension ability would be a wrong choice as it can discourage the reader to complete the task (Case 2012).

There are numerous ongoing discussions of benefits and disadvantages of both with no particular outcome (Green \& Hawkey 2011; Crossley \& McNamara 2016). The decision is always to be taken by a particular tutor based on a particular course and of course student's language competence.

Readability is defined as "The sum total (including all the interactions) of all those elements within a given piece of printed material that affect the success a group of readers have with it. The success is the extent to which they understand it, read it at an optimal speed, and find it interesting" (Dale and Chall 1949, p. 12). This section discusses three different approaches to measuring the level of comprehension of a text using a variety of tools: readability formulas: (1) Flesch-Kincaid Reading Ease formula and Lextutor, (2) intuitive adaptation and (3) reader response).

Readability formulas are utilised to assess reading complexity to identify whether selected text is comprehensible for a specific group of readers. Nowadays there are around 
200 readability formulas (DuBay 2004) that differ in their quality, measurement features, and success (Torki 2013).

Flesch-Kincaid Reading Ease formula is one of the most popular measurement used by a variety of researchers and that is also one of Microsoft Words tools. It calculates readability of a text according to score from 0 to 100 , where 0 means that the text is very difficult to read and 100 stands for its very high readability. In addition, the formula identifies the grade of the assessed reading which indicates the grade-school level the text is accessible for.

Table 1 Flesch-Kincaid Reading Ease score

\begin{tabular}{|c|c|c|}
\hline Score & School grade & Readability \\
\hline $90-100$ & 5 th & Very Easy \\
\hline $80-90$ & 6 th & Easy \\
\hline $70-80$ & 7 th & Fairly easy \\
\hline $60-70$ & 8 th -9 th & Standard \\
\hline $50-60$ & 10 th -12 th & Fairly Difficult \\
\hline $30-50$ & College & Difficult \\
\hline $0-30$ & College graduate & Very Difficult \\
\hline
\end{tabular}

The tool is limited though to a number of features such as text and sentence length, number of sentences and words comprising them, and passive structures. It does not assess the vocabulary of the text which is an essential part of any reading impacting comprehension.

Lextutor was used to fill in the gap in reading ease assessment of the text intended for eliciting reader response. It is an online tool that evaluates lexical complexity of the text. Vocabulary of selected reading is divided into four groups according to their frequency in the language: '(1) the most frequent 1000 words of English, (2) the second most frequent thousand words of English, i.e. 1001 to 2000, (3) the academic words of English (the AWL, 550 words that are frequent in academic texts across subjects), and (4) the remainder which are not found on the other lists' (https://www.lextutor.ca/vp/research.html, para 1).

Research on text difficulty measures vary in terms of classifications and taxonomies. However, there are similar features that are identified by majority of researchers. Tamor (1981) mentions three measures that are vocabulary, syntax and content. There are some considerations here as not all the types of response (objective, behavioural and subjective) can measure each of the mentioned featured equally fairly. For example, if vocabulary and syntax are possible to assess through any of the three types of response, content can definitely not be evaluated objectively (i.e. automatically with a help of any available tools online). Difficulty or appropriateness of content is to be assessed by the tutor or reading material designer. Hence, here intuitive approach is to be considered. Teaching international students involves many different aspects that we need to pay attention to at the time of text selection and amendment. For instance, Islamic culture is particularly sensitive to some content, which might be appropriate in the West.

Response wise the same author (Tamor, 1981) identifies objective, behavioural and subjective difficulty stating that objective text difficulty remains the same whereas behavioural and subjective difficulties will always vary. Murphy (2013) combines all the above-mentioned points establishing a taxonomy that includes three considerations of 
text difficulty assessment. She groups the measurements around the reader and the task, surface and deeper text complexity shifting the focus of hierarchy from objective to subjective difficulty. So, author insists on 'readerability' rather than 'readability' in assessing complexity of the text. Moreover, Murphy introduces another, deeper insight into the text difficulty that requires attention to content (ideas and concepts) as well as Tamor does and goes even further suggesting representational modes as one of the measurements. In comparison, Hervey (2013) provides a classification of three complexity features (based on The Common Core State Standards (CCSS)) to be addressed: qualitative (addressing a mixture of aspects such as layout, language, text structure, etc.), quantitative (addressing vocabulary) and reader-based. Among the three mentioned researchers Sh. Hervey (2013) is the only one who pays attention to the value of tutor's knowledge of his/her students in evaluating text difficulty.

As there is a variety of tools available to the tutor to evaluate text complexity and help amend difficult reading to match multiple requirements of the course and the reader, a logical question to ask would be "Why do we need to seek students' response to provided materials? Do not we know better being equipped with plentiful tools, approaches, strategies and professional experiences of doing so?" The utmost answer to consider would be a list of interrelated advantages provided by reader-based approach. Identifying students' needs through both behavioural and subjective response elicitation would give a tutor the key to the task of improving their (students') reading skills (Berardo 2006; Richards 2018). Considering and comparing the results of performance-based response to the subjective feedback on a variety of text aspects enable the tutor to address identified gaps and help students become confident readers. The result of assessing comprehension as part of the behavioural response equips the tutor with understanding of the students' proficiency as well as lacking knowledge that might be related to a particular text aspect and so, enables him/her to choose a specific strategy of text adaptation that would improve comprehension (Spiegel, 1998; Roberts, 2014; Richards, 2018). Another benefit of reader response consideration is identifying gaps in the knowledge of vocabulary. Obtaining this data via both behavioural and subjective response enables the tutor to address difficulties experienced by the students as well as improve their current vocabulary retention (Hulstijn 1992; Yoshii 2002; Carter \& McCarthy 2014). Moreover, by providing a subjective response to a variety of text related difficulties students apply critical thinking evaluating their own strength and weaknesses (Spiegel 1998; Demeni 2012). Hence, tutors should listen to students' voices attentively to fulfil the task of an educator in a particular environment and to reach the required learning outcomes.

These approaches logically add to one another providing the tutor with valuable points to consider before bringing a text to the classroom. Although priorities of the material designers differ based on the circumstances and personal preferences, they all serve the main purpose of language teaching which is equipping students with necessary skills keeping them motivated and engaged.

\section{Methodology}

\subsection{Reading material selection \& manipulation}

The source of the reading material used for the investigation was a one paragraph text 'Investment strategies' extracted from the $2^{\text {nd }}$ edition of Academic Writing for International Students of Business by Stephen Bailey published in 2015. The choice of the text was 
determined by the sample specialization which is Business and by the needs of a particular course, Academic Reading and Writing, in the framework of which the study was conducted.

Two versions of the text were used for the current study: authentic and adapted.

The text was manipulated based on two grounds: (1) reading ease statistics (FleschKincaid text evaluation and Lextutor vocabulary assessment) that provide objective response on the difficulty of particular elements of the text and (2) opinion of the tutor/researcher who amends the text bearing his/her students' attributes in mind (e.g. their linguistic competence, educational, cultural and religious background).

Text amendments can be classified according to the Green \& Hawkey (2011) taxonomy that includes seven types of text adaptation: deletion, consolidation, expansion, permutation, move, substitution, and insertion. The changes involved were syntactical, grammatical, and lexical (Nikolayeva, 2019) done for the purpose of reading simplification.

E.g.

Diversification must also be considered as an investment strategy. $\rightarrow$ Another strategy is to think about variety.

The above sentence involves four types of amendments: permutation, move, substitution and deletion. First of all, it is permutation that allows a reading material designer to rephrase a challenging part of the text. In this particular case a compound verbal modal predicate ' $\underline{\text { must }}$ be considered' was rephrased using a compound nominal predicate 'is to think'. Due to this change move of the position of the elements (subject - object) within the sentence was involved. In addition, there were two academic vocabulary items substituted by their K1 equivalents: diversification $\rightarrow$ variety and consider $\rightarrow$ think. Finally, the word investment was deleted due to the sentence structure manipulation.

The overall number of amendments of all the seven types of text adaption used to simplify selected reading was forty-eight on the level of both sentence and word/phrase manipulation in the selected one paragraph text.

\subsection{Types of response}

There are three different types of response considered in this paper related to both authentic and adapted text: objective (OR), behavioural (BR), and subjective (SR) (Tamor 1981).

Objective response to text difficulty is obtained with the help of text evaluation tools available online as per the reading materials designer's preferences. The current study uses statistics of Flesch-Kincaid text assessment that focuses on the surface features (Murphy 2013) of text complexity, such as word, sentence and text length as well as passive structures. Flesch-Kincaid statistic does not provide any vocabulary evaluation. Hence, another automated tool, Lextutor, is involved in the study to obtain objective response on the text vocabulary complexity. It provides vocabulary statistics in the form of frequency-based word lists (Cobb 2018). According to this tool the lexis of the text is divided into $\mathrm{K} 1, \mathrm{~K} 2$, academic and off-list words. Based on the objective response the tutor can decide about the suitability of a text to a specific group of students.

The second type of response is behavioural. It is a performance-based text difficulty evaluation that was obtained with the help of a test. The first task of the test administered to the students included ten multiple choice items with four response options each that aimed at testing the knowledge of vocabulary used in the provided reading. The words 
were drawn from the text and varied in difficulty. Majority belonged to K1 group: apply, buy, difficulty, business, consider, problem; two words were K2 lexical items (manager, risk), and two represented academic word list (income, financial). The choice was made based on Lextutor vocabulary evaluation tool.

The second task of the test aimed at assessing students' reading comprehension. It consisted of five multiple choice questions on the text content that involved recognition of the info expressed through variety of grammatical structures.

The students worked on the text in the mode of sustained, silent, self-paced reading (Spiegel 1998). There were no time limitations set due to several reasons. First of all, every student has a different speed of reading. Secondly, comprehension needs time. Finally, absence of time constrains reduces test anxiety and provides comfortable environment.

The last type of response was students' subjective feedback on the text complexity elicited with the help of a survey that focused on general evaluation of text difficulty and assessment of complexity of a specific aspect of the text (i.e. vocabulary, sentence structure, grammar). In terms of general text reading ease the students were asked to use Likert scale to evaluate the reading choosing an option from the range of five between 'very difficult' to 'very easy'. The same approach was used for identifying the groups' opinion on three specific text aspects. This kind of response would enable the tutor to estimate the success of adaptation and consider any further improvements that might be required in the future.

\subsection{Research sample}

The subjects of the research were Arab students, i.e. an international group as compared to native speakers.

Data collected from two groups of students. Group 1 consisted of 23 and Group 2 of 31 students. All of the participants were students of Business department who study the course of Academic Reading and Writing. For consistency full time students only were chosen for the study to avoid any deviations in response. The reason is that part timers have richer background as well as personal and professional experience that would be different from full timers who are recent school graduates.

Table 2 Students profile

\begin{tabular}{|c|c|c|c|c|c|}
\hline \multicolumn{2}{|l|}{ Info } & \multicolumn{2}{|c|}{ Group 1} & \multicolumn{2}{|c|}{ Group 2} \\
\hline \multirow{2}{*}{ Gender } & Male & 9 & $39.1 \%$ & 9 & $29 \%$ \\
\hline & Female & 14 & $60.9 \%$ & 22 & $71 \%$ \\
\hline \multirow{4}{*}{ Age } & $18-20$ & 8 & $34.8 \%$ & 13 & $41.9 \%$ \\
\hline & $21-23$ & 12 & $52.2 \%$ & 18 & $58.1 \%$ \\
\hline & $24-26$ & 2 & $8.7 \%$ & 0 & $0 \%$ \\
\hline & $27+$ & 1 & $4.3 \%$ & 0 & $0 \%$ \\
\hline \multirow{2}{*}{ Type of students } & Normal & 21 & $91.3 \%$ & 23 & $74.2 \%$ \\
\hline & Retake & 2 & $8.7 \%$ & 8 & $25.8 \%$ \\
\hline \multicolumn{2}{|c|}{ Pre-requisite course mean } & \multicolumn{2}{|c|}{60.3} & \multicolumn{2}{|c|}{54.26} \\
\hline \multicolumn{2}{|c|}{$\begin{array}{l}\text { Programme specific courses } \\
\text { taken/in progress }\end{array}$} & \multicolumn{4}{|c|}{$\begin{array}{l}\text { Introduction to financial/business accounting; } \\
\text { Principles of management; Principles of economics } \\
\text { Principles of Marketing; IT applications for } \\
\text { business; Business mathematics and statistics }\end{array}$} \\
\hline
\end{tabular}


As per their demographic profile majority of students in both of the groups were females. Half of them in Group 1 as well as in Group 2 (52.2\% and 58.1\% respectively) were between $21-23$ years of age. It means that the sample have similar educational background restricted to their schooling and a number of courses they took or are currently taking. The courses taken or in progress are Basics of Economics, Management, Marketing and Accounting as well as Mathematics and Statistics. All of them are taught in English solely. This course profile leads to an assumption that the sample are equipped with basic business vocabulary required to successfully proceed with their studies in current courses. It is also worth mentioning that the percentage of retake students in Group $2(25.8 \%)$ was considerably higher than in Group 1 $(8.7 \%)$. This might be a ground to hypothesise that the results mean of the second group would be low. The difference in mean (60.3 for Group 1 students vs 54.26 for Group 2 students) in Integrated language skills course, treated as pre-requisite to Academic reading and writing module, determined the choice of the text difficulty level in each of the cases. Group 1 was tested on the authentic reading material whereas Group 2 worked with the adapted text.

\section{RESULTS}

Collected data includes three types of response to text difficulty: objective, behavioural and subjective response (see Types of response). There were two versions of the text 'Investment strategies' (Bailey 2015) involved into the study. The first one is authentic reading and the second one is its adapted version. Two groups of Arab students participated in the study (see Research sample). Group 1 provided their behavioral and subjective response to authentic reading and Group 2 worked on the manipulated version of the text.

The below analysis presents a comparison of authentic and adapted reading based on each of the types of response.

\subsection{Objective response}

Objective response to text difficulty was the first type of the response considered in the present study. Both of the texts (authentic and adapted) were evaluated with the help of two tools: Flesch-Kincaid reading ease statistics was utilised to identify the readability of selected reading material and Lextutor helped examining the complexity of the text vocabulary (see Table 3 ).

Table 3 Comparison of Flesch-Kincaid statistics of authentic and adapted texts

\begin{tabular}{|l|c|c|}
\hline Flesch-Kincaid statistics & Authentic text & Adapted texts \\
\hline Words & 208 & 213 \\
Sentences & 13 & 18 \\
Words per sentence & 16 & 11.8 \\
Passive sentences & $7 \%$ & $0 \%$ \\
Flesch reading ease & 35.2 & 61.3 \\
Flesch-Kincaid grade level & 12.3 & 7.6 \\
\hline
\end{tabular}

According to Flesch-Kincaid calculation reading ease of the authentic text was identified as 35.2 out of 100 . This falls within the range of $50-30$ meaning that the text is very difficult to read. Grade level of the text in question is 12.3 , which is higher than top grade school level for a native speaker. 
The text was manipulated based on the provided statistics, vocabulary analysis and the opinion of the tutor. The reading ease of the text increased from the authentic 35.2 to 61.3 , which is within the range of 70-60 out of 100 . It means that the adapted text can be easily understood by 13 - to 15 -year-old students, who are $8^{\text {th }}-9^{\text {th }}$ grade native speakers.

Total number of words increased slightly (208 to 213) as a result of sentence structure amendment applied during the adaptation process. As for the count of sentences in the text, their number increased from thirteen to eighteen. Consequently, as some of the sentences in the text were modified from compound or complex ones into simple ones to ensure better comprehension, the number of words per sentence decreased from sixteen to almost twelve.

Passive sentences comprised $7 \%$ of the authentic text and were all modified and substituted by the Active Voice structures.

As Flesch-Kincaid statistics is limited to particular features of the text, Lextutor (see Types of response) was used for assessing vocabulary difficulty of the text. According to this tool lexical items used in the reading are divided into four different groups based on their usage frequency. They are K1 words, which are the first 1000 most used lexical items, K2 the second 1000 most frequent words, academic word list (AWL) and off-list words are the least frequently used vocabulary items and considered to be difficult for understanding.

Table 4 presents comparative statistics on the vocabulary complexity between the authentic and adapted reading.

Table 4 Comparison of vocabulary complexity of authentic and adapted texts

\begin{tabular}{|l|c|c|}
\hline Type of vocabulary & Authentic text & Adapted text \\
\hline K1 & $75 \%$ & $88.37 \%$ \\
K2 & $6.13 \%$ & $6.51 \%$ \\
Academic vocabulary & $15.09 \%$ & $4.65 \%$ \\
Off-list vocabulary & $3.77 \%$ & $0.47 \%$ \\
\hline
\end{tabular}

The number of $\mathrm{K} 1$ words increased considerably to enable better reading comprehension. Authentic text contained $75 \%$ of the most frequently used lexical items whereas in its manipulated version the percentage increased to $88.37 \%$. The amount of $\mathrm{K} 2$ words remained close to its percentage in the original and changed from $6.13 \%$ to $6.51 \%$. The number of Academic word list identified by Lextutor in the authentic reading was $15.09 \%$. After the adaptation it decreased to $4.65 \%$ The changes were considered carefully by the tutor based on the familiarity with the language competence and educational background of the students participating in the research. Off-list vocabulary was mostly substituted by K1 words and its percentage reduced considerably from $3.77 \%$ to $0.47 \%$.

\subsection{Behavioural response}

Behavioural response to text difficulty was elicited with the help of test. It consisted of two sections where the first section assessed student knowledge of vocabulary found in the selected reading and the second one focused on comprehension. The Table below presents comparative statistics of the performance by the sample where one group was tested on the authentic reading and the other - on its manipulated version. The Table demonstrates the percentage of correct and incorrect answers to each of the test sections followed by their mean. 
Table 5 Behavioural response to text difficulty

\begin{tabular}{|l|c|c|c|c|}
\hline \multirow{2}{*}{ Task } & \multicolumn{2}{|c|}{ Authentic text } & \multicolumn{2}{c|}{ Adapted text } \\
\cline { 2 - 5 } & Correct & Incorrect & Correct & Incorrect \\
\hline 1 & $46.08 \%$ & $53.92 \%$ & $73.54 \%$ & $26.46 \%$ \\
2 & $48.69 \%$ & $51.31 \%$ & $60.64 \%$ & $39.36 \%$ \\
\hline Mean & $47.39 \%$ & $52.61 \%$ & $67.09 \%$ & $32.91 \%$ \\
\hline
\end{tabular}

As the Table above shows, the first group who worked on authentic reading demonstrated lower results as compared to the second group, who were tested on the adapted text. Around than half of Group 1 students answered the test tasks correctly $(46.08 \%$ in case with Task 1 and $48.69 \%$ in case with Task 2). The other half of the sample working tested on the authentic reading provided incorrect answers $(53.92 \%$ in case with Task 1 and $51.31 \%$ in case with Task 2). Group 2 showed better performance in the test. $73.54 \%$ of the students provided correct answers to the vocabulary task and $60.64 \%$ answered comprehension questions correctly. The first task related to the vocabulary used in the text appeared to be less challenging for the students than comprehension questions as only $26.46 \%$ provided incorrect answers to Task 1 compared to $39.36 \%$ of wrong answers in Task 2.

The above results demonstrate direct relation between objective and behavioural responses to text difficulty, i.e. the students showed a behavioural response of higher quality to adapted text and a considerably lower performance on the authentic reading. However, it is worth noting that Group 2, who worked on the adapted reading did not show a $100 \%$ result on any of the tasks which means that the text contained challenging elements that affect the sample response.

\subsection{Subjective response}

Subjective response to text difficulty was obtained with the help of a survey administered after the test. Both groups were asked to evaluate provided reading complexity based on fivepoint Likert scale. Table 6 demonstrates opinion of the sample on each of the versions of the text (authentic and adapted) in comparison.

Table 6 Subjective response to text difficulty

\begin{tabular}{|c|c|c|c|c|c|c|c|}
\hline \multirow[b]{2}{*}{ Aspect } & \multirow{2}{*}{$\begin{array}{l}\text { Text } \\
\text { type }\end{array}$} & \multicolumn{5}{|c|}{ Scale } & \multirow{2}{*}{$\begin{array}{c}\text { Total } \\
\%\end{array}$} \\
\hline & & $\begin{array}{c}\text { Very difficult } \\
\%\end{array}$ & $\begin{array}{c}\text { Difficult } \\
\%\end{array}$ & $\begin{array}{c}\text { Neither } \\
\text { easy nor } \\
\text { difficult } \\
\%\end{array}$ & $\begin{array}{c}\text { Easy } \\
\%\end{array}$ & $\begin{array}{c}\text { Very } \\
\text { easy } \\
\%\end{array}$ & \\
\hline \multirow{2}{*}{$\begin{array}{l}\text { Overall text } \\
\text { difficulty }\end{array}$} & AUT & 39.13 & 30.43 & 21.76 & 4.34 & 4.34 & $100 \%$ \\
\hline & ADT & 12.9 & 19.35 & 32.26 & 19.35 & 16.14 & $100 \%$ \\
\hline \multirow[t]{2}{*}{ Vocabulary } & AUT & 52.2 & 26.1 & 8.7 & 8.7 & 4.3 & $100 \%$ \\
\hline & ADT & 9.6 & 12.9 & 42 & 22.6 & 12.9 & $100 \%$ \\
\hline \multirow{2}{*}{$\begin{array}{l}\text { Sentence } \\
\text { structure }\end{array}$} & AUT & 13.1 & 27.7 & 43.5 & 11.4 & 4.3 & $100 \%$ \\
\hline & ADT & 12.9 & 25.8 & 25.8 & 19.3 & 16.2 & $100 \%$ \\
\hline \multirow{2}{*}{ Grammar } & AUT & 26.09 & 21.73 & 34.78 & 8.7 & 8.7 & $100 \%$ \\
\hline & ADT & 22.6 & 29 & 19.3 & 12.9 & 16.2 & $100 \%$ \\
\hline
\end{tabular}


The Table above shows the data on subjective response to four aspects of text difficulty by two groups involved in the research: overall text difficulty, vocabulary, sentence structure and grammar difficulty. Group 1 worked with an authentic text and Group 2 worked with an adapted text. The students were surveyed on the reading ease of the provided text according to the Likert scale where they choose among five levels of difficulty: very difficult, difficult, neither difficult nor easy, easy and very easy. They had to use their own judgement when completing the survey.

\section{Overall text difficulty}

Authentic text was considered very difficult (39.13\%) and difficult (30.43\%) by majority of the students which makes it $69.56 \%$ in total, whereas only $8.68 \%$ considered it easy/very easy. This difference reflects on the results of Flesch-Kincaid statistics which defined the text as difficult to read. The rest of the group $(21.76 \%)$ considered the text neither difficult nor easy.

Adapted text difficulty, on the other hand, was evaluated by a similar number of students as very difficult /difficult (32.25\%) and easy/very easy (35.49\%). Current results could be a reflection of the lower strength of Group 2 that has $25.8 \%$ students who were retaking this course due to their unsuccessful performance in the previous semester. Hence, it can be assumed that their language skills are lower than of other students of the same group, which resulted in the current estimation of the text ease.

\section{Vocabulary difficulty}

Vocabulary of the authentic text was considered very difficult $(52.2 \%)$ and difficult $(26.1 \%)$ by most of the participants, i.e. total of $78.3 \%$ identified lexical items used int in the reading as challenging.

Adapted text vocabulary, on the contrary, was perceived by a big group of students $(42 \%)$ as neither difficult nor easy. $35.5 \%$ felt that it was easy/very easy and only $22.5 \%$ said it was difficult/very difficult.

Sentence structure difficulty

According to the Group 1, sentence structure did not cause any comprehension difficulties. $43.5 \%$ evaluated the authentic text syntax as neither difficult nor easy. $40.8 \%$ of the students of Group 1 considered it difficult/very difficult. Only 15.7\% said it was easy/very easy.

As for Group 2 who worked on the manipulated version of the reading, 38.7\% of the respondents considered it difficult/very difficult while $35.5 \%$ said it was easy/very easy. The remaining $25.8 \%$ were neutral.

Current results demonstrate approximately equal division of each of the surveyed groups into students who are familiar and not familiar with syntactical structures used in the text.

Grammar difficulty

Grammatically, both of the texts appeared almost equally challenging for the students. $47.82 \%$ of Group 1 said that the authentic reading was difficult/very difficult which is close to the opinion of Group 2 where $51.6 \%$ were of the same opinion. This demonstrates the need for specific attention to grammatical structures at the point of adaptation. Opinions of the other half of the respondents split between neutral response to grammar complexity of the text and its easy/very easy option with its inclination to the first among Group 1 students and the second among Group 2 participants. 
The results confirm an idea that text manipulation towards simplification can sometimes cause an opposite effect and make comprehension more difficult (Crossley et.al, 2014).

\subsection{Comparison of behavioural vs subjective responses}

Table 7 presents comparison of two types of response to text difficulty: behavioural and subjective. The results were divided into positive and negative kinds of response. Positive behavioural response $(\mathrm{BR}(+))$ is the mean percentage of correct answers to test tasks whereas negative response $(\mathrm{BR}(-))$ is the mean of incorrect answers. As for the subjective response, positive response $(\mathrm{SR}(+))$ includes the mean percentage of students who said the text was neither easy nor difficult, easy or very easy. Negative subjective response (SR(-)) includes students' evaluation of the text as difficult and very difficult.

Table 7 Behavioural vs subjective response to text difficulty: comparison

\begin{tabular}{|l|c|c|c|c|}
\hline \multirow{2}{*}{ Response type } & \multicolumn{2}{|c|}{ Authentic text } & \multicolumn{2}{c|}{ Adapted text } \\
\cline { 2 - 5 } & Positive & Negative & Positive & Negative \\
\hline Behavioural response & $45.21 \%$ & $54.79 \%$ & $62.28 \%$ & $37.42 \%$ \\
Subjective response & $30.44 \%$ & $69.56 \%$ & $67.75 \%$ & $32.25 \%$ \\
\hline
\end{tabular}

Presented statistics allows us to compare students' subjective opinion on the reading ease to their actual performance. In case with the authentic text used with Group 1 it can be seen that the students underestimated their strengths as the percentage of their $\mathrm{SR}(+)$ is lower than $\mathrm{BR}(+): 30.44 \%$ vs $45.21 \%$. So, the rate of their underestimation is around $14.8 \%$. It means that they considered given text more difficult than it actually was according to the results of their performance in the test. On the other hand, Group 2, who worked with adapted reading, slightly overestimated their skills where their performance proved otherwise. Group $2 \mathrm{SR}(+)$ was around 5\% higher than their BR(+). The results of negative response, both $\mathrm{BR}(-)$ and $\mathrm{SR}(-)$ were proportional to the positive response of the students. Therefore, it can be noted that linguistically stronger students tend to doubt their abilities more than weaker ones.

\section{CONCLUSION}

The paper presented a discussion of students' response to text adaptation. Two groups of Arab business students were investigated. All of the students had similar background, were placed within the same age, and represented both genders.

The objective, behavioural and subjective response to authentic and manipulated text difficulty was compared. The tools chosen for the study were a test and a survey. Both of the tools aimed at assessing students' text comprehension and their knowledge of different types of vocabulary.

The research reveals direct relation between OR, BR and SR to the text complexity. As the study demonstrated the authentic reading was defined as challenging by OR which was confirmed by the results of the of both the BR of the sample and their SR of Group1 who were tested on the basis of the above-mentioned text. Although Group 1 obtained good results in the pre-requisite course, their performance in the test demonstrated a 
number of difficulties they faced completing it, such as vocabulary meaning recognition and comprehension where unfamiliar grammatical structures were involved.

The analysis of OR, BR and SR on manipulated text showed similar relationship. It means that the students performed considerably better on the simplified version of the text. Hence, text adaptation is required for Arab undergraduate students based on their, specialization, level of intervention, and performance in the pre-requisite course.

Students' specialization is another variable that needs attention of the tutor as it can be a ground for adaptation/non-adaptation of specific aspects of the original text. For instance, current research focused on business students. Therefore, business specific vocabulary was retained in the text at the time of adaptation, although, it was identified by the vocabulary assessment tool as academic and could be substituted in cases where a different course is targeted.

Students' achievement in prerequisite course/-s serves well as another source of information for a tutor working on reading materials design. One should consider the strengths and weaknesses of the group working on the course design as it can directly impact further progress of the students. If students' prerequisite course results are remarkably low or high the tutor might choose the way he/she adapts the text accordingly.

Level of intervention completed by the time of using an amended text needs careful consideration. Inclusion/exclusion of particular lexical items, syntactic or stylistic structures directly depends on whether they were taught in class or not as well as how elaborate the intervention was. The tutor should ensure that the text difficulty matches students' current linguistic and professional background.

There is a clear relationship between BR and SR depending on the text ease. The results of text adaptation are reflected in both better performance and subjective difficulty evaluation. Comparison of behavioral and subjective responses demonstrated that students tend to underestimate their knowledge and/or exaggerate text difficulty. Their performance appears to be better than understanding of their own strengths and abilities. This factor can be used as the ground for particular choices to be made by the tutor in the process of reading manipulation towards moderate simplification.

The quality of the text ease assessment in general as well as specific aspects of it are directly related to reader response results. Positive response to adaptation depends on careful identification of problematic text areas \& choice of manipulation approaches. A blend of objective and subjective reading ease assessment is of great importance here as the tutor needs to consider a number of personal and professional variables in process of text amendment. This approach would ensure a positive impact on learner's performance.

Vocabulary was identified as the most challenging aspect of the text. It intervened with students understanding of the content. Hence, vocabulary development is an essential part of language acquisition that should be addressed as a vital part of any language course.

A combination of both OR and tutor's opinion to adaptation can benefit the quality of manipulated reading materials as automated tools of text difficulty assessment do not consider a set of personal and professional characteristic of a particular group of students. No doubt, the results of objective text evaluation are important and of great help for a tutor, however, one has to apply his/her own judgement to ensure multifaceted appropriateness of reading for their students. 


\section{REFERENCES}

Berardo, S. A. 2006. "The use of authentic materials in the teaching of reading." The reading matrix, 6, 2, 60-69.

Carter, R., \& McCarthy, M. 2014. Vocabulary and language teaching. Routledge. London: Longman.

Case, A. 2012. Advantages and disadvantages of using authentic texts in class. [Online] Available from https://www.usingenglish.com/articles/advantages-disadvantages-usingauthentic-texts-in-class.html [Accessed 15 Janury 2018].

Cobb, T. 2018. "Why and how to use frequency lists to learn words." Lextutor.ca. [Online] Available from https://www.lextutor.ca/research/ [Accessed on 31 December 2018]

Crossley, S.A. and McNamara, D.S. 2016. "Text-based recall and extra-textual generations resulting from simplified and authentic texts." Reading in a Foreign Language, 28, 1, 1-19.

Crossley, S.A., Yang, H. S., \& McNamara, D.S. 2014. "What's so simple about simplified texts?" Reading in a Foreign Language, April, 26.1, 92-113.

Dale, E., \& Chall, J. S. 1949. "The Concept of Readability.” Elementary English 26, 1, 19-26.

Demeni, P. 2012. "Developing written text production competence using the readerresponse method". Acta didactica napocensia, 5, 3, 53-60.

DuBay, W.H. 2004. The Principles of Readability. CA: Costa Mesa. [Online] Available from: http://www. impact-information.com/impactinfo/ readability02.pdf [Accessed on 21 November 2019].

Goodman, K., \& Freeman, D. 1993. "What's simple in simplified language." In M.L. Tikko (Ed.), Simplification: theory and application. Singapore: SEAMEO Regional Language Centre, 69-81.

Green, A., \& Hawkey, R. 2011. "Re-fitting for a different purpose: A case study of item writer practices in adapting source texts for a test of academic reading." Language Testing, 29.1, $109-129$.

Hervey, S. 2013. "A beginner's guide to text complexity." Generation ready. [Online] Available from http://www.generationready.com/wp-content/uploads/2014/02/BeginnersGuide-to-Text-Complexity.pdf [Accessed on 31.12.2018]

Hulstijn, J. H. 1992. "Retention of inferred and given word meanings: Experiments in incidental vocabulary learning." In Vocabulary and applied linguistics. UK: Palgrave Macmillan, 113-125.

Krashen, S. 1988. Second Language Acquisition and Second Language Learning. US: Prentice-Hall International.

Kuimova M. V., Kobzeva N. A. 2011. "Advantages and Disadvantages of Authentic Materials Use in EFL Classrooms.” Молодой ученьй 3.2, 125-127. [Online]. Available from https://moluch.ru/archive/26/2844/ [Accessed 11 January 2018].

Long, M., \& Ross, S. 1993. "Modifications that preserve language and content.” In M. L. Tickoo (Ed.), Simplification: Theory and application. Singapore: SEAMEO Regional Language Center, 29-52.

Murphy, S. 2013. "Assessing text difficulty for students." What works? Research into Practice, Research monograph \#44, January. [Online]. Available from http://www.edu. gov.on.ca/eng/literacynumeracy/inspire/research/ww_atds.pdf [Accessed on 31.12.2018] 
Nikolayeva, L. 2019. "Adapting a text for testing purposes: approach to academic reading and writing assessment design in the Middle East." Theory and practice in language studies, 9, 2, 204 - 216.

Richards, J. C. 2018. Advantages and disadvantages of using instructional materials in teaching ESL. [Online] Availible from: https://www.professorjackrichards.com/ advantages-and-disadvantages-of-using-instructional-materials-in-teaching-esl/ [Accessed 15 January 2018]

Roberts, R. 2014. Authentic or graded? [Online] Availible from: https://elt-resourceful.com/ 2014/02/27/authentic-or-graded-is-there-a-middle-way/ [Accessed 15 January 2018]

Spiegel, D. L. 1998. "Reader response approaches and the growth of readers." Language arts, 76, 1, 41-48.

Tamor, L. 1981. "Subjective text difficulty: an alternative approach to defining the difficulty level of written text." Journal of reading behavior, 8, 2, 165 - 172.

Torki, S. 2013. "Algerian University English Language Teaching Materials: How readable are they?" AWEJ, 4, 4, 4-16.

Yoshii, M., \& Flaitz, J. 2002. "Second language incidental vocabulary retention: The effect of text and picture annotation types." CALICO journal, 20, 1, 33-58. 